\title{
BALLISTIC AND PHYSICAL PROPERTIES OF HIGHLY FRACTURED ALUMINA
}

\author{
I. Horsfall, M. R. Edwards and M. J. Hallas
}

\begin{abstract}
It is known that ceramic materials in armour are often shattered by a penetrating projectile and the resistance to penetration is therefore dependent upon the properties of this failed material. A small explosive charge was used to shatter a confined $95 \%$ alumina tile by passing the stress wave from an explosive detonation through a steel cover plate and into the ceramic. This fractured material was shown to have an elastic modulus of $130 \mathrm{GPa}$ compared to $330 \mathrm{GPa}$ for the monolithic alumina. Impact indentation tests and ballistic depth of penetration tests were performed on the intact ceramic, shattered ceramic and a pressed ceramic powder compact. It was found that the fractured material had a ballistic efficiency approximately $70 \%$ of that of the monolithic alumina and was also able to cause significant erosion to the projectile.
\end{abstract}

Keywords: Ballistic test; mechanical properties; indentation hardness; ceramic armour.

\section{INTRODUCTION}

Armours that contain one or more layers of ceramic material, are common in vehicle, aircraft and personal armour systems. The high compressive strength of the ceramic is exploited to promote disruption, erosion and resistance to penetration of the projectile. Although the processes of penetration have been widely studied and modelled there remains some doubt as to the exact properties of the ceramic material in the regions nearest to the penetrating projectile. The armour material close to the point of penetration sees very large strains [1] which are accommodated by plasticity and flow in metallic armours. It has been shown [2] that in the case of ceramics extensive cracking takes place under the projectile, producing a granular rubble which supports the load imposed by the projectile. Shokey et al [3] state that the presence of this densely cracked zone ahead of the penetrator is a prerequisite for penetration. They go on to state that confinement of this rubble by the surrounding material creates an effective barrier to penetration and the resistance of this material to flow by interparticle sliding is an important factor in the effectiveness of the armour [3]. The role of confinement has been recognised and methods which measure properties under confinement similar to the conditions of ballistic impact have been used [4] but there is still a shortfall in the understanding of the properties of the shattered material.

A number of studies have attempted to characterise this shattered material in order to include the effects within numerical models [5] or to provide other parameters which characterise target resistance [6]. High-strain post-yield properties of brittle materials are difficult to measure as conventional test methods are not applicable, so it is necessary to use either indirect or novel methods to determine mechanical properties. 
Indentation methods have been proposed as a means to determine strength parameters in an extension of the conventional hardness test [7]. These methods are particularly relevant to the current case as the mechanics of indentation have obvious similarities to projectile penetration. An initial approach that could be adopted is to calculate target strength by a simple hardness equation for an indenter being driven into a sample. Hardness can then be expressed as the ratio of applied load to the projected area of the indentation.

Elastic constants such as Young's modulus and Poisson's ratio may be estimated by measurement of elastic wave speeds [8]. Ultrasonic test equipment, usually used for flaw detection, can be used to generate longitudinal or shear waves. Measurement of the time of flight of these two types of wave, combined with an accurate knowledge of the transit distance, allows the longitudinal wave speed $V_{L}$ and the shear wave speed $V_{S}$ to be determined. From the wave speeds and the material density $(\rho)$ it is then possible to calculate elastic properties according to

$$
\text { Young's modulus } E=\rho V_{T}^{2} \frac{3 V_{L}^{2}-4 V_{T}^{2}}{V_{L}^{2}-V_{T}^{2}}
$$

$$
\text { Shear modulus } \quad G=\rho V_{T}^{2}
$$

$$
\text { Poisson's ratio } \quad v=\frac{\left(V_{L} / V_{T}\right)^{2}-2}{2\left[\left(V_{L} / V_{T}\right)^{2}-1\right]}
$$

Penetration resistance can be determined from ballistic tests using methods such as residual depth of penetration (DoP) [9]. From these results it is possible to determine the mass efficiency factors (MEF) of armour materials and the minimum thickness required to just stop the penetrator $\left(\mathrm{t}_{\mathrm{CRIT}}\right)$. It should be noted that the MEF values will be relative to the backing block material.

$$
\begin{aligned}
& M E F=\frac{P_{B} \rho_{B}}{\rho_{A} t_{A}+P_{R} \rho_{B}} \\
& t_{\text {crit }}=\frac{t_{C} P_{B}}{\left(P_{B}-P_{R}\right)}
\end{aligned}
$$

where

$\mathrm{P}_{\mathrm{B}} \quad$ penetration of the backing block in isolation

$\mathrm{P}_{\mathrm{R}} \quad$ residual penetration of the backing (after the candidate material)

$\rho_{\mathrm{B}, \mathrm{A}}, \quad$ density of backing block and candidate material respectively.

$\mathrm{t}_{\mathrm{C}} \quad$ thickness of candidate material. 
In the present work an attempt is made to produce complete tiles of shattered ceramic in order to mimic the transient material state which exists during the penetration process. This material is then characterised in terms of its microstructure, elastic, indentation and ballistic properties. Ballistic and instrumented impact tests are then performed on the shattered material and compared to similar tests carried out on unfractured ceramic and to samples made by compressing a raw powder.

\section{EXPERIMENTAL}

\section{Materials preparation}

The experimental programme aimed to develop a reproducible method to produce shattered material similar to that which might exist ahead of a penetrating projectile. The starting material chosen for the work was 95\% alumina (Sintox FA, Morgan Matroc Ltd) in tiles measuring $50 \mathrm{~mm}$ x 50mm and with thicknesses of $6 \mathrm{~mm}$ or $25 \mathrm{~mm}$. This has a hardness of HV 1200 and a density of $3700 \mathrm{kgm}^{-3}$.

The action of a penetrating projectile is to drive a high amplitude compressive wave into the ceramic and it is this and its subsequent reflections which causes the material to shatter. In order to fracture the ceramic but retain it in place it is necessary to provide a confinement system to prevent spalling or gross cracking, and so a steel containment frame was produced to hold the tiles. This consisted of mild steel blocks of the same thickness as the tile securely bolted to a high hardness steel backing plate. A further high hardness steel cover plate (Compass B555, Sleeman Engineering) of hardness HV 464 was used to provide confinement to the tile front and to allow the accurate positioning of a detonator in contact with the centre of the plate surface. Although the detonators were capable of either breaking or locally shattering the ceramic tile, the effect was too localised and did not cause extensive shattering below the surface of the tile.

Direct explosive loading was shown to produce too much disruption to the ceramic surface so a cover plate was then used to communicate the shock load but prevent direct contact between the ceramic and the explosive. The ceramic tile was raised so that its surface was approximately $2 \mathrm{~mm}$ above the surrounding steel surface and a steel plate was then placed against it. The steel plate used was of mild steel of hardness HV 140 and measuring $80 \mathrm{~mm}$ x $80 \mathrm{~mm} \times 10 \mathrm{~mm}$. A charge of $5 \mathrm{~g}$ of PE4 explosive (88\% RDX $12 \%$ wax) was shaped in to a disc of $40 \mathrm{~mm}$ diameter and $2 \mathrm{~mm}$ thick. This was placed centrally on top of the metal plate and was then initiated by an electrical detonator placed vertically in the centre of the plate. This arrangement provided a ceramic material which had negligible tensile strength but retained its shape.

In order to allow further ballistic trials without disturbing this shattered material a confinement rig was constructed based on the design of Sherman and Ben-Shushan [10]. This rig which is illustrated in figure 1 , uses a series of adjustable wedge blocks to provide in-plane confinement of the tile and incorporates a space behind the tile which can house a witness block to allow measurement of residual depth of penetration. For explosive shattering the thickness of the backing block was adjusted such that the face of the ceramic tile was approximately $1 \mathrm{~mm}$ above the face of the confinement rig. 


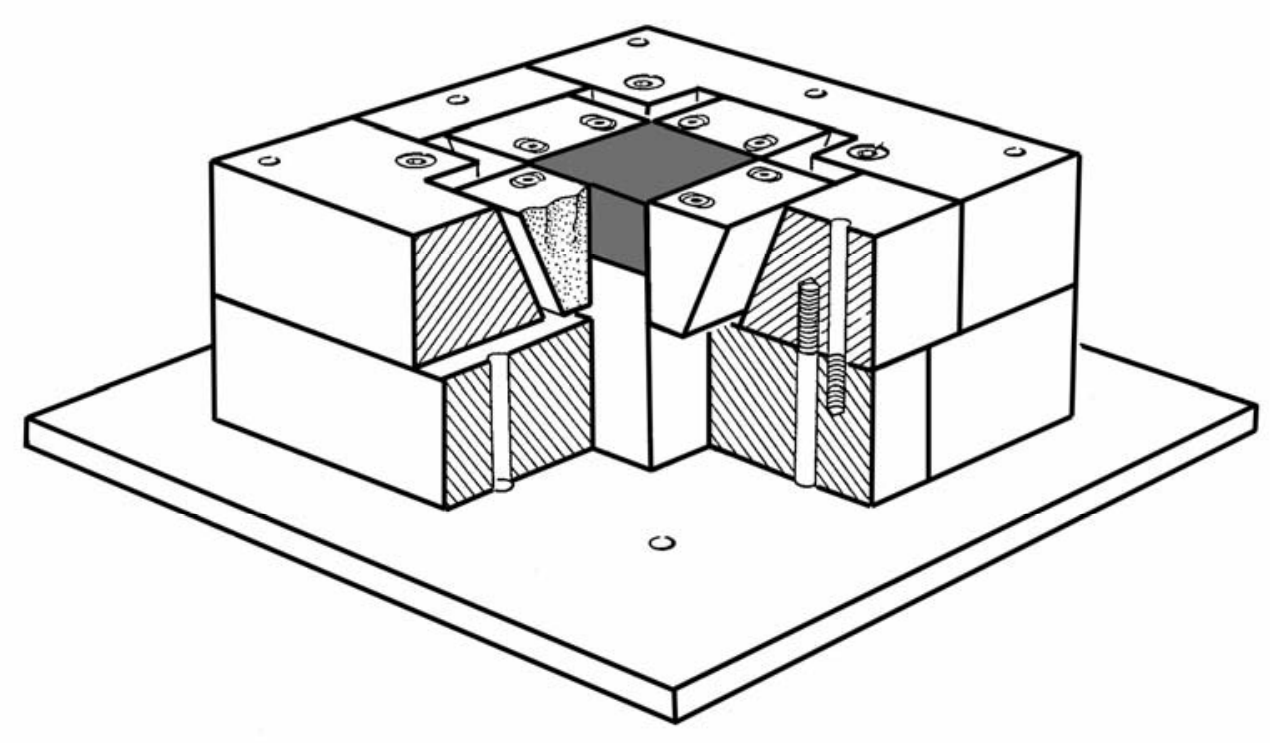

Figure 1. The confinement rig used to hold alumina tiles during the fracturing process and during ballistic testing.

For comparison with the shattered material, alumina powder compacts were also pressed in-situ in the same rig. A set of $50 \mathrm{~mm}$ high blocks were bolted to the front face to extend the height of the central $50 \mathrm{~mm} \times 50 \mathrm{~mm}$ space. A die tool was manufactured which could be pressed into this space. Pressed powder tiles were produced by first pouring a known amount of alumina powder into the die. Next the plunger was slid into the die and then a press was used to compress the powder. These tiles were pressed from pure alumina powder with mean particle size of $80 \mu \mathrm{m}$, and pressed to a pressure of $40 \mathrm{MPa}$. This produced a material of $67 \%$ of theoretical density, i.e. containing 33\% porosity.

\section{Physical property tests}

The shattered and compressed powder tiles had only negligible tensile strength making conventional mechanical testing difficult, therefore ultrasonic wave propagation was used to provide measurement of elastic constants. In this study the shear wave was generated using a normal incident shear wave probe and the longitudinal wave was generated using a Wells-Krautkramer twin crystal compression wave probe. The shattered and pressed ceramic tiles demonstrated a high attenuation to typical ultrasonic test frequencies $(\sim 4 \mathrm{MHz})$ so a low frequency $(54 \mathrm{kHz})$ system was used in some tests.

In order to use this procedure the material density was accurately measured together with thickness and planarity of the opposing faces. Elastic constants were then derived using equations $(1-3)$. More details of the test method are given by Topp[11].

\section{Ballistic tests}

The penetration resistance of the three materials was assessed by a ballistic residual depth of penetration method. Trials were conducted using 7.62 x $51 \mathrm{~mm}$ AP FFV ammunition manufactured by Bofors $\mathrm{AB}$. This projectile has a typical muzzle velocity of $950 \mathrm{~ms}^{-1}$, and has a tungsten carbide core within a soft metal jacket. The core has a hardness of $\mathrm{Hv}$ 1250, a diameter of $5.6 \mathrm{~mm}$ a length of $20.2 \mathrm{~mm}$. The core has a truncated conical tip of $60^{\circ}$ included angle with a $0.6 \mathrm{~mm}$ diameter flat nose. The 
complete projectile and its core are shown in figure 2a. More information on the projectile and its penetrative performance is given by Horsfall [12].

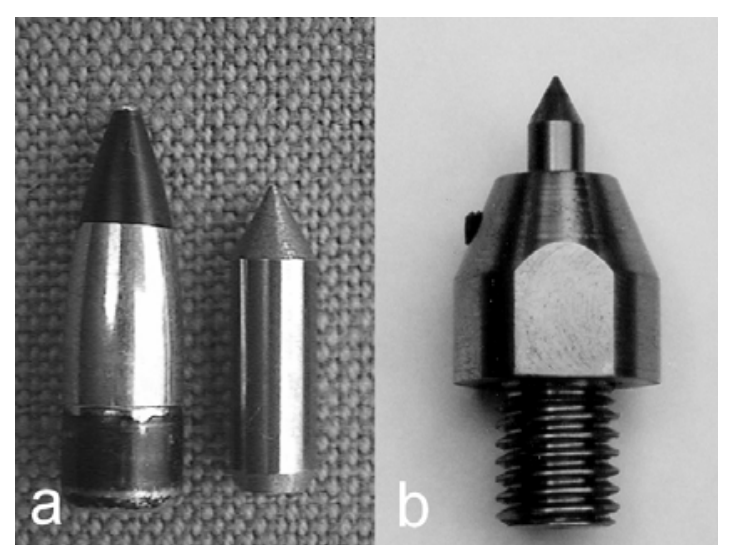

Figure 2 a) 7.62mm FFV bullet and its core,

b) the core mounted in a holder for impact tests.

Shattered tiles and pressed powder tiles were produced in the confinement rig with a 75 mm thick aluminium alloy 7018-T6 block of hardness HV 150 placed behind them in the rig. The thickness of the three tiles was selected to achieve the same areal density (mass per unit area) between the three types, therefore for the intact ceramic and explosively shattered tiles $6 \mathrm{~mm}$ thickness was used and for the pressed powder $9 \mathrm{~mm}$ tiles where used. Tests were conducted at a range of $10 \mathrm{~m}$ with the weapon accurately sighted so that the projectiles struck the centre of the tile. After ballistic tests the backing block was removed for examination and the residual penetration was measured by either mechanical sectioning or X-ray imaging of the block.

\section{Impact tests}

As an alternative method to measure penetration resistance the tungsten carbide core of the FFV projectile detailed above was used as an indenter and driven into the tile samples using an instrumented drop tower. The indenter and its holder are shown in figure 2b. Impact testing was performed on an IFW-8 accelerated instrumented falling weight machine produced by Rosand Precision Ltd. The drop mass was $4.5 \mathrm{~kg}$ with an impact speed of $4 \mathrm{~ms}^{-1}$. The axial force on the penetrator was measured using a piezoelectric load cell positioned immediately behind the indenter and the velocity at impact was recorded. Force-time data and impact velocity were then used to derive the velocity, force, and displacement profiles of the impact events. From the force data measured in the impact tests an assessment of the mean yield pressure was determined.

\section{RESULTS}

After explosive shattering the tiles had negligible tensile strength and could be broken or crumbled by hand to a fine powder. There was a very slight increase in tile thickness after shattering, whilst in plane expansion was resisted by the confinement rig. Although a small decrease in density was measured this is within the range specified for the intact material. The confinement rig provided a convenient holder in which to produce the 
materials and then carry out subsequent ballistic test without disassembly. Dilation of the shattered material produced good contact and rigid confinement from the walls. A similar effect was gained during pressing of the powdered material. For the block ceramic the clamping wedges were tightened sufficiently to achieve good contact with the rig faces. Consequently all the tests could be conducted on materials having similar degrees of confinement.
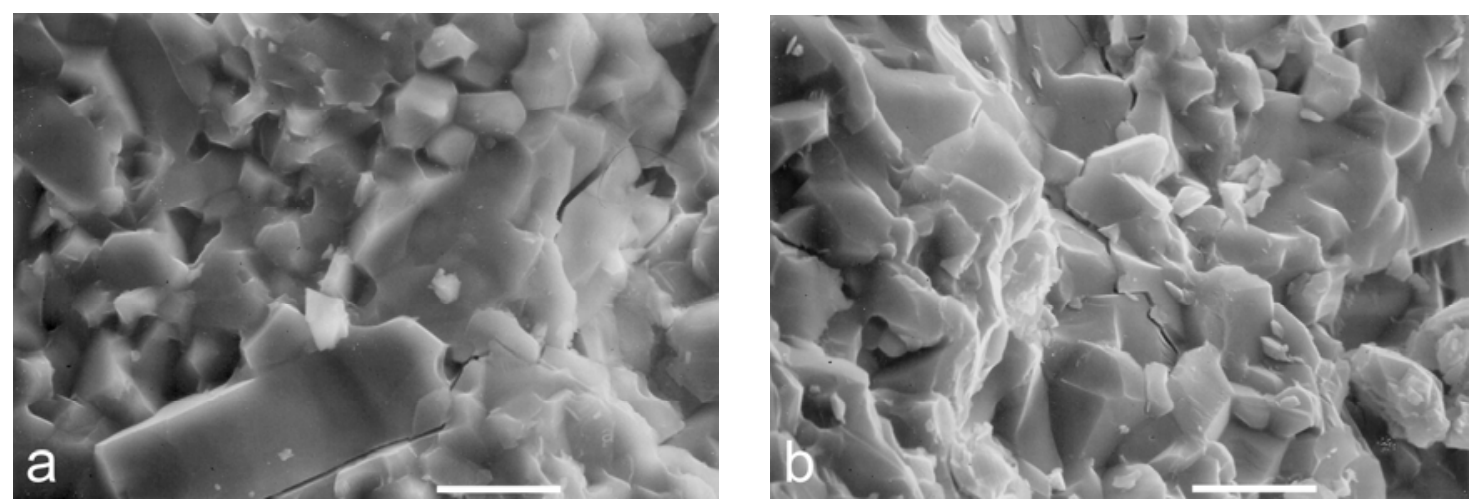

Figure 3. Electron micrographs of a) block ceramic after ballistic impact and b) explosively shattered ceramic. Scale markers are $10 \mu \mathrm{m}$.

\section{Microscopy}

Samples of the intact and explosively shattered tiles were examined in optical and scanning electron microscopes. The grain size of the unfractured tiles was approximately $5 \mu \mathrm{m}$ which is within the manufacturer's specified range for the material $(2.80-6.00 \mu \mathrm{m})$. The explosively shattered material showed evidence of extensive microcraking with a particle size of approximately 10micron. Figure 3 shows electron micrographs of a fracture surface of the intact material after ballistic testing and a fracture surface of the explosively shattered material. It can be seen that in both cases there is extensive fracturing but little displacement of the fractured particles. There was widespread intergranular cracking and some evidence of transgranular cracking. The particle shapes where angular and faceted with the same appearance as the original grains. The pressed powder consisted of spherical particles with diameters of between $50 \mu \mathrm{m}$ and $150 \mu \mathrm{m}$.

Table 1 Physical properties measured derived from ultrasonic measurements.

\section{Elastic properties}

The results of the ultrasonic tests are shown in table 1 and compared to the manufacturers specification for the intact ceramic in brackets. These showed that the intact tile had a measured Young's modulus within the limits of the manufacturer's specification and close to reference values for similar alumina ceramics. This provides some confidence in the ultrasonic test method. For the shattered material the longitudinal and shear moduli decreased by $60 \%$ (compared to the intact material) and for the pressed powder the values decreased by approximately $98 \%$. 
Table 1 Physical properties measured derived from ultrasonic measurements.

\begin{tabular}{|l|c|c|c|}
\hline & $\begin{array}{l}\text { Intact ceramic } \\
\text { (Specification) }\end{array}$ & $\begin{array}{l}\text { Shattered } \\
\text { ceramic }\end{array}$ & $\begin{array}{l}\text { Pressed } \\
\text { powder }\end{array}$ \\
\hline $\begin{array}{l}\text { Thickness } \\
(\mathrm{mm})\end{array}$ & 24.98 & 25.02 & 9.61 \\
\hline $\begin{array}{l}\text { Density } \\
\left(\mathrm{kgm}^{-3}\right)\end{array}$ & $\begin{array}{c}3816 \\
(3670-3880)\end{array}$ & 3809 & 2544 \\
\hline $\begin{array}{l}\text { Longitudinal wave } \\
\left.\text { velocity (ms }{ }^{-1}\right)\end{array}$ & 10408 & 6410 & 1513 \\
\hline $\begin{array}{l}\text { Shear wave velocity } \\
\left(\mathrm{ms}^{-1}\right)\end{array}$ & 5868 & 3670 & 1035 \\
\hline $\begin{array}{l}\text { Poisson's ratio } \\
\text { Shear modulus } \\
(\mathrm{GPa})\end{array}$ & 0.27 & 0.26 & 0.06 \\
\hline $\begin{array}{l}\text { Young's modulus } \\
(\mathrm{GPa})\end{array}$ & $\begin{array}{c}333 \\
(325-336)\end{array}$ & 129 & 5.8 \\
\hline
\end{tabular}

\section{Ballistic tests}

Tests were first conducted on thick tiles of each or the materials $(25 \mathrm{~mm}$ intact and shattered, $37.5 \mathrm{~mm}$ thickness pressed powder). The intact ceramic was penetrated approximately $17 \mathrm{~mm}$ and the shattered ceramic was penetrated approximately $25 \mathrm{~mm}$, in both cases the backing block was not penetrated. For the pressed powder the projectile completely penetrated the tile and then penetrated $25 \mathrm{~mm}$ into the backing block. Tests were then conducted on thinner tiles (6mm intact and shattered, 9mm thickness pressed powder). X-ray photographs of the penetrators embedded in the aluminium backing block are shown in figure 4 . Residual penetration for the intact tiles was $21 \mathrm{~mm}$, for the shattered tile $34 \mathrm{~mm}$, and for the pressed powder $40 \mathrm{~mm}$. The latter is only slightly less than the $42.5 \mathrm{~mm}$ penetration achieved into the bare backing block. Erosion of the tungsten carbide penetrator can be seen for projectiles having penetrated the block ceramic and, to a lesser extent, in the explosively shattered material, but was absent in the pressed powder (although the penetrator was broken).

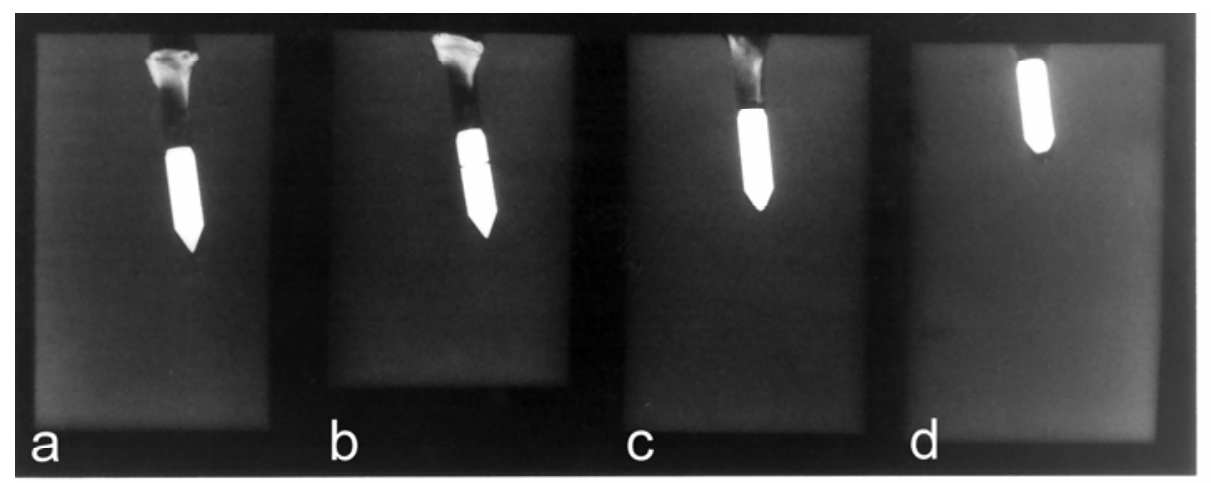

Figure 4. X-ray of penetrators embedded in aluminium after impact on a) aluminium block only, b) pressed powder ceramic, c) explosively shattered ceramic and d) block ceramic. 


\section{Impact tests}

At least two samples were tested in each condition. Repeatability between tests was good; for two tests using block ceramic samples the peak loads were $21.95 \mathrm{kN}$ and $22.13 \mathrm{kN}$ whilst for the shattered ceramic peak loads of $17.68 \mathrm{kN}$ and $18.51 \mathrm{kN}$ were measured. Examples of the load vs. time data are shown in figure 5. The pressed powder showed a different behaviour with an initial low broad peak in the first 2-3ms followed by a ramp up to similar loads to the other samples.

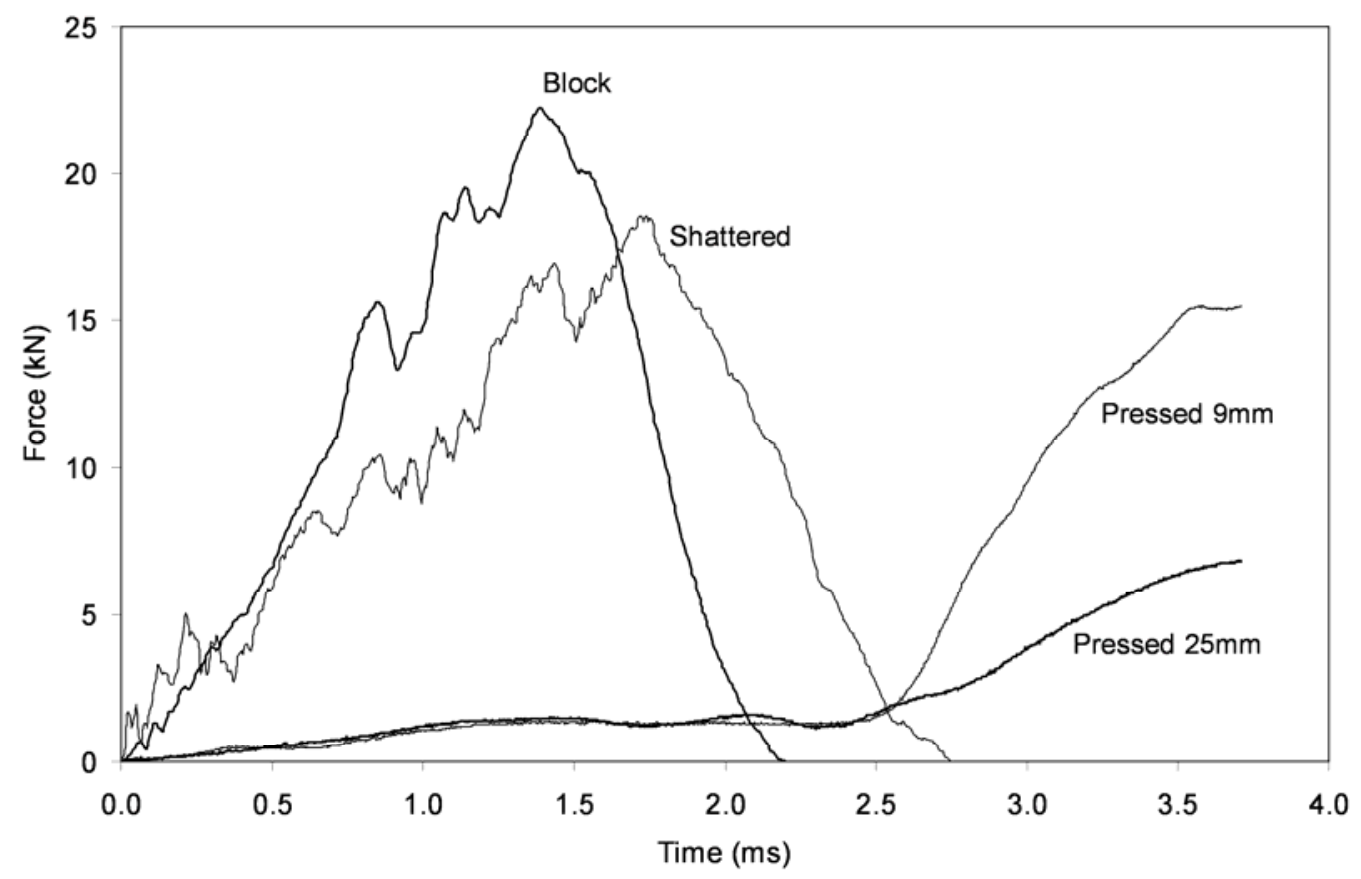

Figure 5. Axial force on penetrator measured during drop weight impact tests on each material.

However it was determined that the start of the later ramp corresponded to full embedment of the indenter with the subsequent rising load occurring as the face of the steel holder was pushed into the surface. However up to the start of the ramp the two data sets for the powdered sample are very similar and the subsequent divergence is due to the different thicknesses of the two samples (9mm and $25 \mathrm{~mm}$ ).

\section{DISCUSSION}

The explosive shattering process produces a material with an appearance at a microscopic level similar to that of formerly intact ceramic close to a ballistic impact. Extensive fracturing is produced so that the material is reduced to an almost fully compacted powder of approximately the same particle size as the original intact material grain size. However this is different from a compacted powder because although most grain boundaries are fractured the fractures are closed and the particles are effectively interlocked. Tensile strength is reduced to negligible levels such that although the material can be handled and retains its shape it can also be reduced to a fine powder by crumbling between the fingers.

The pressed powder samples showed very low levels of physical and mechanical properties. This was partially the result of being unable to provide sufficient compaction 
pressure within the rigs. However a further factor was the powder particle form. The fine grade powder which was chosen had spherical particles which would not produce the resistance to flow that would be associated with an in situ fractured material. Whilst it might have been more appropriate to use an angular powder, one was not available and the increase in flow resistance afforded by an angular powder would have reduced the ability to produce a low porosity compact. Therefore the results for the compacted powder should be taken as simply indicative of the properties of a highly porous system.

\section{Ballistic tests}

Erosion of the penetrator, as shown by Woodward [2], can reduce the effectiveness of the penetration process, since penetrator erosion is a key component of the defeat mechanism. In the present work explosive shattering is shown to reduce ballistic performance by approximately 30\% whilst the mechanical and impact tests suggest a reduction of approximately 25\%. Previous work [13] has shown that depth of penetration tests into semi-infinite targets may not truly represent the performance of a practical armour material. In practical systems the ceramic is relatively thick compared to the backing and the longer path length through the ceramic increases the importance of the projectile erosion. It should also be noted that the un-fractured material has a hardness, which is only marginally greater than the penetrator, and therefore none of the three materials would be expected to be very effective.

Although the shattered material may have similar properties to that which is created during ballistic impact it lacks the constraint which would be supplied by the surrounding tiles in a practical armour system. The lower modulus of the shattered material combined with a high degree of attenuation of stress waves might also reduce the effectiveness of stress waves reflected from the interface with the confinement rig.

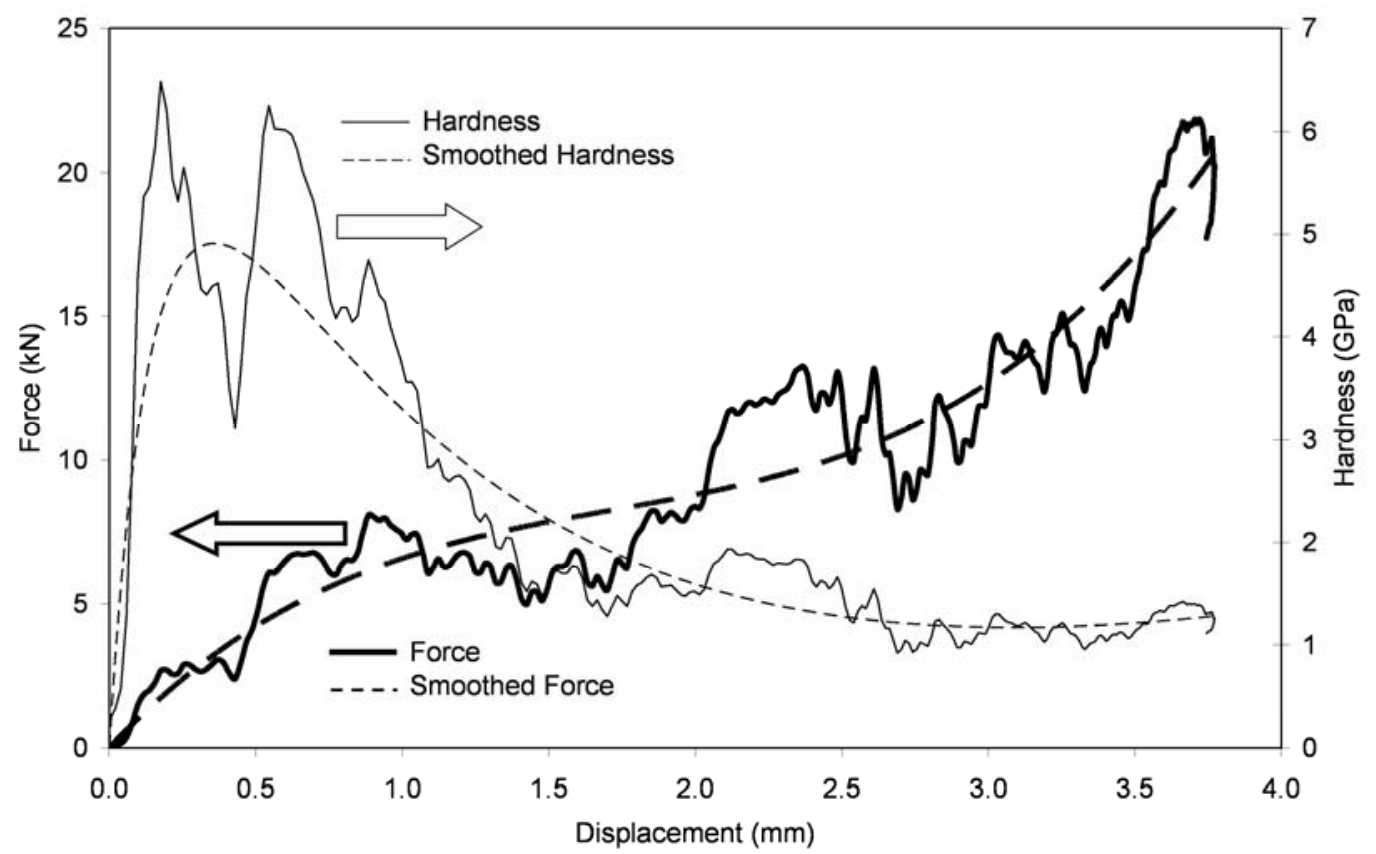

Figure 6. Load vs. displacement plot for an intact ceramic block showing the hardness derived directly from the load or from the polynomial fit to the load data. 
The ability of the shattered material to flow will be a function of the confinement arrangements and particle shape, with the most heavily confined materials being the most effective in preventing flow of material, and, hence, the most efficient armour. The shattered material, although highly fractured, preserves good mechanical contact between particles and the angular nature of these particles would be expected to produce a high resistance to flow. This is in contrast to the pressed powder that exhibited larger inter particle gaps (33\% by volume) with only point contact between the particles.

\section{Impact tests}

The data from the impact test were used in an indentation analysis. The presented area of the indenter in contact with the target was calculated incrementally with penetration into the sample and from this the hardness was calculated. Figure 6 shows the data from a single test on an intact ceramic sample. The hard initial contact produced in the test produces large load oscillations. Direct determination of the hardness from this data is difficult to interpret so a polynomial fit was applied to the force data and this was then used to derive the hardness

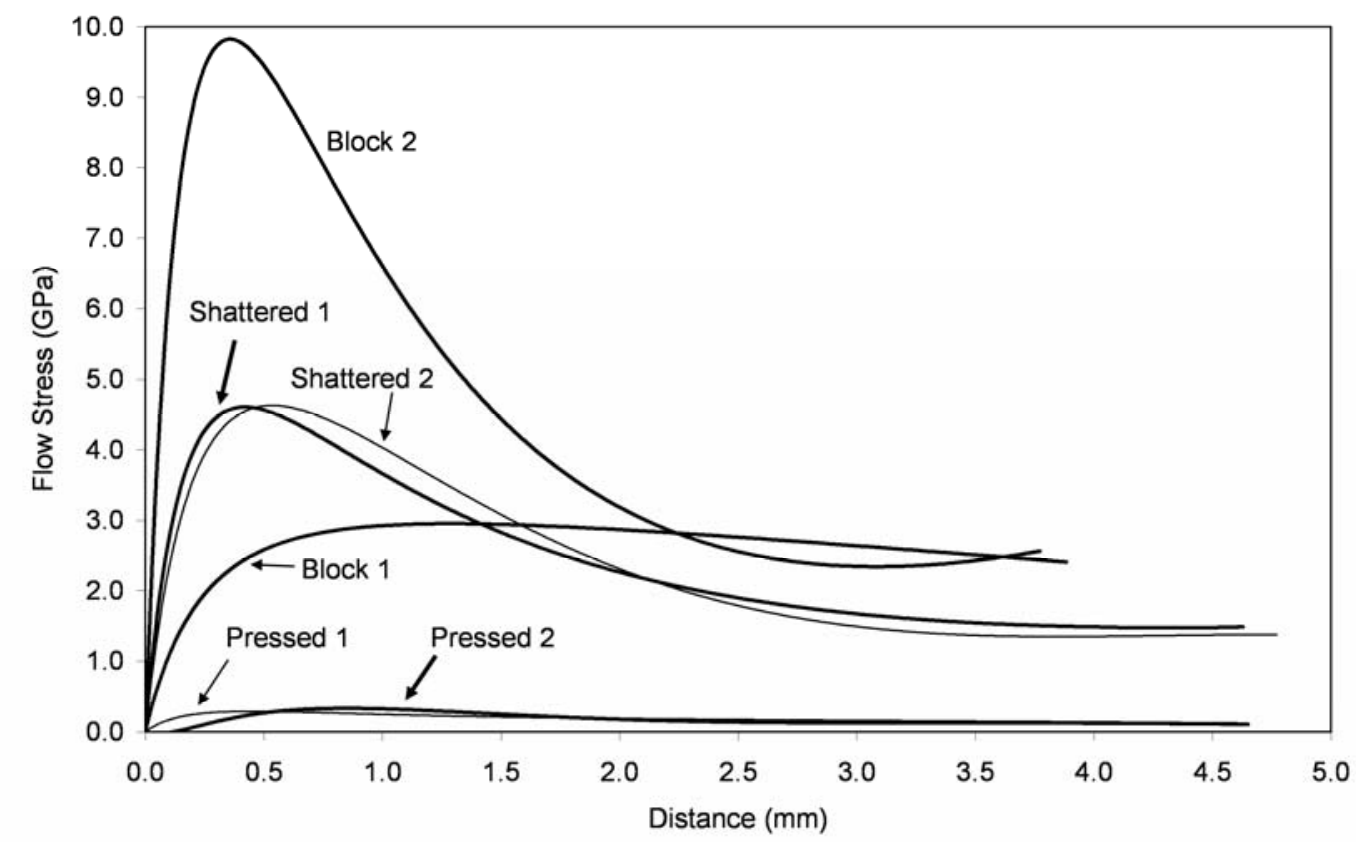

Figure 7. Apparent hardness derived from fitted load data and shown for pairs of samples in each condition

Figure 7 shows the hardness plots for all the tests derived from polynomial fits of the force data. Although some of the tests show a large peak in the apparent hardness at small displacements this is unduly influenced by the initial perturbations in the load force cause by the initial contact. The later plateau is less influenced by the initial contact and appears repeatable. It is clear that the plateau value is very similar for each pair of tests and is probably a characteristic of the sample type. The level of the plateau was assessed as the average hardness over the range $3 \mathrm{~mm}-4 \mathrm{~mm}$ displacement for each of the tests and this is shown in table 2. 
Table 2 Summary of ballistic test results and hardness data

\begin{tabular}{|l|c|c|c|}
\hline & Intact ceramic & $\begin{array}{c}\text { Explosively } \\
\text { shattered }\end{array}$ & $\begin{array}{c}\text { Pressed } \\
\text { powder }\end{array}$ \\
\hline DoP (mm) & 21 & 34 & 40 \\
\hline MEF (relative to Al 7018 T6) & 1.46 & 1.01 & 0.88 \\
\hline Critical tile thickness (mm) & 11.9 & 30 & 102 \\
\hline Indentation depth (mm) & 3.8 & 4.7 & NA \\
\hline Indentation load (kN) & 21.9 & 18.0 & NA \\
\hline Apparent hardness (GPa) & 1.23 & 0.74 & 0.068 \\
\hline
\end{tabular}

The hardness values are surprisingly low; for instance, the apparent hardness of the intact ceramic is $1.23 \mathrm{GPa}$ whilst the Vickers hardness of Sintox FA is HV 1200 which translates to 11.8GPa in SI units. However the apparent hardness measured here is for a sharp indenter which has significantly penetrated the tile and caused large strains in the adjacent material. Consequently it is penetrating a shattered material which should be in a similar state to that in the pre-shattered samples.

Although it is possible to deduce a flow stress from the hardness data this would require a detailed understanding of the indentation process. The relationship of hardness to uniaxial strength is a function of the elastic-plastic behaviour of the sample [14]. In addition a typical hardness test uses a relatively blunt indenter in order to minimise any frictional effects. For sharper indenters an allowance for friction should properly be used [15], but the friction coefficient is difficult to determine experimentally. It is doubtful whether Coulomb friction is applicable for cases involving contact stresses significantly above the material yield strength. Muscat-Fenech [16] notes that in cases such as this the friction coefficient becomes no more than an empirical constant. .

Studies on indentation of rock [17] typically show a saw-toothed form to the load vs. displacement trace as shear planes develop and relieve the load. In the present study, although there is some oscillation of the load it does not have the characteristics or amplitude of this shear or chipping process. This observation suggests that the shattered material is flowing under the action of the indenter and not simply shearing. This in turn suggests that the combination of interlocking particles and significant confinement produces a material of high shear resistance which forms an effective barrier to a penetrating projectile.

Explosive shattering results in a reduction in all properties; ballistic performance drops by approximately 30\%, and apparent hardness by slightly more and elastic moduli reduce by at least $60 \%$. For the pressed powder there is a similar trend but with an even greater spread, ballistic performance drops by $40 \%$ and moduli by more than $95 \%$ compared to the intact material. This is probably to be expected as the difference in properties between the intact and shattered materials before impact should be very large. But during impact the intact material will rapidly damage so that its properties approach those of the pre shattered material.

The observed difference in ballistic performance may in part be due to the poorer confinement of the pre-shattered material. Although the confinement rig provided good support in the plane of the tile and towards the rear face there is no confinement on the front face. Therefore the shattered material was able to crater extensively on the front 
face and this reduces the support adjacent to the projectile. A better test might be to shoot the projectile through a relatively small aperture in a thick cover plate or even to penetrate through the cover plate as has been done in other studies. [3]

Clearly the ability of the shattered material to flow will be a function of the confinement arrangements and particle shape, with the most heavily confined materials being the most effective in preventing flow of material, and hence the most efficient armour. The shattered material, although highly fractured, preserves good mechanical contact between particles and the angular nature of these particles would be expected to produce a high resistance to flow. This is in contrast to the pressed powder that exhibited larger inter particle gaps (33\% by volume) with only point contact between the particles.

\section{CONCLUSIONS}

An explosive shattering process in combination with a confinement rig has been demonstrated. This method provides a means to synthesise fractured ceramic of a similar condition to that found immediately adjacent to a penetrating projectile.

The elastic properties of shattered alumina and pressed powder are shown to reduce by approximately $60 \%$ and $98 \%$ respectively when compared to intact material.

The ballistic properties of shattered and pressed powder compacts have been measured by DoP test and are reduced by $30 \%$ and $40 \%$ respectively compared to the intact material. The relatively small reduction in ballistic properties is due to the rapid reduction in the intact materials properties as it is shattered during penetration.

\section{REFERENCES}

1. R.L. Woodward, Penetration of targets by conical projectiles, Int. J. mech. Sci., 20:349-359, 1978.

2. R.L. Woodward, W.A. Gooch Jr., R.G. O'Donnel, W. Perciballi, B.J. Baxter, S.D. Pattie, A study of fragmentation in the ballistic impact of ceramics, Int. J. Impact Engng, 15:605-618, 1994

3. D.A. Shockey, A.H. Marchand, S.R. Skaggs, G.E. Cort, M.W. Burkett, R. Parker, Failure phenomenology of confined ceramic targets and impacting rods, Int J Impact Engng, 9:263-275, 1990 4. S. Chocron, K.A. Dannemann, J.D. Walker, A.E. Nicholls, C.E. Anderson Jr., Constitutive Model for Damaged Borosilicate Glass Under Confinement, J. Am. Ceram. Soc., 90 (8):2549-2555, 2007. 5. T.J. Holmquist, G.R. Johnson, Modeling prestressed ceramic and its effect on ballistic performance, Int. J. Impact Engng, 31 (2): 113-127, 2005

6. Yu. K. Bivin. Penetration of Rigid Bodies into Loose and Layered Media, Mechanics of Solids, 43 (1):131-136. 2008.

7. A. G. Atkins and D. Tabor, Plastic indentation in metals with cones, J. Mech. Phys. Solids, 13:149164, (1965).

8. J. and H. Krautkramer,: Ultrasonic Testing of Materials, Springer-Verlag, Berlin, 1977.

9. Z. Rozenberg, Y. Yeshurun, The relationship between ballistic efficiency and compressive strength of ceramic tiles, Int. J. Impact Engng, 7 (3):357-362, 1988

10. D. Sherman. T. Ben-Shushan, Quasi-static impact damage in confined ceramic tiles, Int. J. Impact Engng, 21:245-265, 1997

11. K. Topp, A simple ultrasonic technique for the practical determination of E-modulus in glass ceramic armour tiles, Insight, 36 (12):949-952, 1994.

12. I. Horsfall, N. Ehsan, W. Bishop, A comparison of the performance of various light armour piercing ammunition, J. Battlefield Tech, 3 (3):5-8, 2000

13. I.Horsfall, W. Bishop, D, Cowan, The effect of ceramic type on the performance of ceramic faced metallic armour, J. Battelfield tech. 6 (3):1-4, 2003 
14. M. Mata, M. Anglada, J. Alcalá, A hardness equation for sharp indentation of elastic-power law strain-hardening materials, Phil. Mag. A, 82(10):1831-1839, 2002

15. R. F. Bishop, R. Hill, N. F. Mott, The theory of indentation and hardness tests, Proc. Phys. Soc., 57 (3):147-159, 1945.

16. C. M. Muscat-Fenech, A. G. Atkins, Denting and fracture of sheet steel by blunt and sharp obstacles in glancing collisions, Int. J. Impact Engng, 21 (7):499-519, 1998.

17. B. Lundberg, Penetration of Rock by Conical Indenters. Int. J. Rock Mech. Min. Sci. \& Geomech. Abstr., 11:209-214, 1974 